\title{
Technology use and learning characteristics of students in higher education: Do generational differences exist?
}

\section{Kwok-Wing Lai and Kian-Sam Hong}

Kwok-Wing Lai is professor of Education in the College of Education at the University of Otago. He is also the director of the Centre for Distance Education and Learning Technologies and editor of Computers in New Zealand Schools. Kian-Sam Hong is professor of Education in the Faculty of Cognitive Sciences and Human Development and Centre for Applied Learning and Multimedia, Universiti Malaysia Sarawak, Malaysia. Address for correspondence: Professor Kwok-Wing Lai, University of Otago College of Education, 145 Union Street East, Dunedin 9054, New Zealand.Email: wing.lai@otago.ac.nz

\begin{abstract}
As digital technologies form an inextricable part of young people's everyday lives, some commentators claim that the current generation of learners think and learn differently from their predecessors. This study investigated the validity of this claim by surveying 799 undergraduate and 81 postgraduate students at a large research-intensive university in New Zealand to document their use of digital technologies on university and social activities and comparing three age groups of students (under 20, 20-30 and over 30) to see whether there were any differences in their learning characteristics. The findings of the study showed that while students spent a large amount of time on digital technologies, the range of digital technologies they used was rather limited. There were also no practical generational differences in the technology use pattern and learning characteristics found in this study. The results of this study suggest that generation is not a determining factor in students' use of digital technologies for learning nor has generation had a radical impact on learning characteristics of higher education students.
\end{abstract}

\section{Introduction}

University teachers will agree that a good understanding of the learning characteristics of their students is a key factor affecting the decision of what and how pedagogies will be employed in their teaching and that it will ultimately impact on the success of their students' learning (Laurillard, 2002). With the exponential growth of digital technologies in recent years, there is no doubt that in economically advanced countries, many young people have accumulated a huge amount of technology experience before they enter university. For example, one survey in the USA (Rideout, Foehr \& Roberts, 2010) reported that in 2009, 8-18-year-olds spent on average four and a half hours daily using digital technologies out of school. They used their mobile phones and computers to do text messaging, talk to peers, listen to music, play games and watch other media, with the three most popular online activities being visiting social networking sites (eg, MySpace and Facebook), playing computer games and watching videos on websites (Lai, Khaddage \& Knezek, 2013). These technology experiences undoubtedly will affect the way young people play, communicate, socialise and learn. Some commentators (eg, Oblinger \& Oblinger, 2005; Palfrey, Gasser, Simun \& Barnes, 2009; Prensky, 2001a, 2011b; Rosen, 2010; Tapscott, 2009) even go as far as suggesting that as a result of being surrounded by and immersed in technologies, there is a fundamental difference between how the current generation of young people learn, as compared with previous generations. These so called digital natives have a 